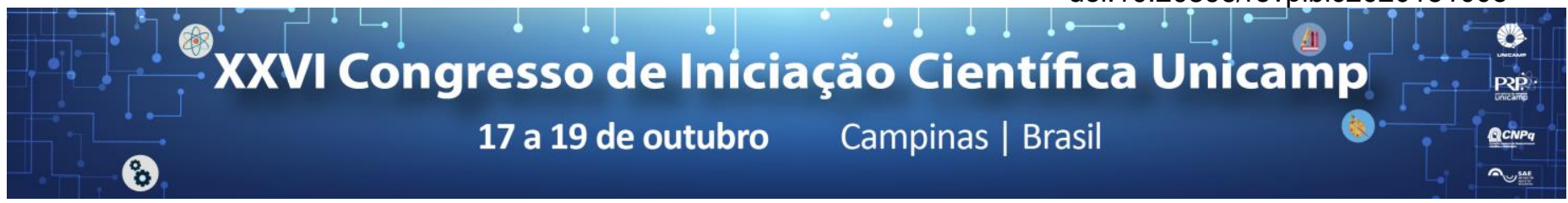

\title{
Análise Comparativa de Variações Espaciais da linha de costa do Nordeste da llha do Cardoso
}

\section{Marina Betetto Drezza*, Pedro Michelutti Cheliz, Regina Celia de Oliveira.}

\begin{abstract}
Resumo
A linha de costa da llha do Cardoso, situada no Complexo Lagunar Cananéia-Iguape do litoral sul de São Paulo, possui fortes oscilações em períodos cronológicos recentes, possíveis de serem representados em documentos cartográficos que apontem a dinâmica de funcionamento dos processos no limite da linha de costa.

Esta pesquisa dá ênfase na análise da oscilação da linha de costa no setor nordeste da llha, onde os processos apontam para maior oscilação dos limites da linha de costa, fato pode indicar maior nível de instabilidade e efeito evolutivo dos processos morfodinâmicos do período de 2000 a 2016, por períodos quinquenais.
\end{abstract}

Os resultados, permitiram criar correlações com os trabalhos realizados na mesma área por CHELIZ (2015), comprovando a dinâmica de evolução dos processos no limite da linha de costa.

\section{Palavras-chave: \\ Mapeamento geomorfológico, Ilha do Cardoso, Oscilações litorâneas}

\section{Introdução}

Considerando a dinâmica de funcionamento dos limites costeiros, e o impacto dos processos oceanográficos, continentais e atmosféricos na organização de novas formas de relevo, o setor nordeste da llha do Cardoso se mostrou como espaço importante de investigação, dado a possibilidade de construção cartográfica recente que permitisse o registro das oscilações da linha assistidas nas ultimas décadas.

A área localiza-se entre latitude $25^{\circ} 11^{\prime} 6^{\prime \prime} \mathrm{S}$ e longitude $47^{\circ} 59^{\prime} 43^{\prime \prime}$ como demonstrado na imagem 1 ao lado.

\section{Resultados e Discussão}

A metodologia da pesquisa foi a utilização do programa ArcGis e a ferramenta DSAS, com ela foi implantado transectos por toda a linha de costa e houve uma comparação com os resultados de Cheliz (2015). Foram desenvolvidas tabelas, gráficos e mapas para assim haver uma comparação visual com a teoria. (ver mapa 1 ao lado). Ao comparar as linhas de costa representadas no mapa, os pontos em que há uma maior oscilação são a Ponta Norte e a região da barra.

Os resultados apontam para um variação significativa da linha de costa nos períodos mapeados corroborando com as afirmação de Cheliz (2015), onde a parte de mar aberto possui uma dinâmica de oscilações maiores ao longo do tempo, do que a parte da laguna, tanto de progradação ou retrogradação, sendo que nos últimos anos tem predominado a retrogradação tanto na laguna quanto na barra.

\section{Conclusões}

Os dados apresentados nesse trabalho em conjunto com correlações a resultados bibliográficos sobre mesma temática, nos permite destacar a dinâmica em que se processa a esculturação dos processos erosivos e construtivos na linha de costa da área de estudo.

Houve a conclusão já esperada por conta dos trabalhos de Cheliz (2015) e a confirmação dos mesmos, mas com muito mais detalhes do que o planejado, deixando a pesquisa muito mais significativa para futuros estudiosos da área.

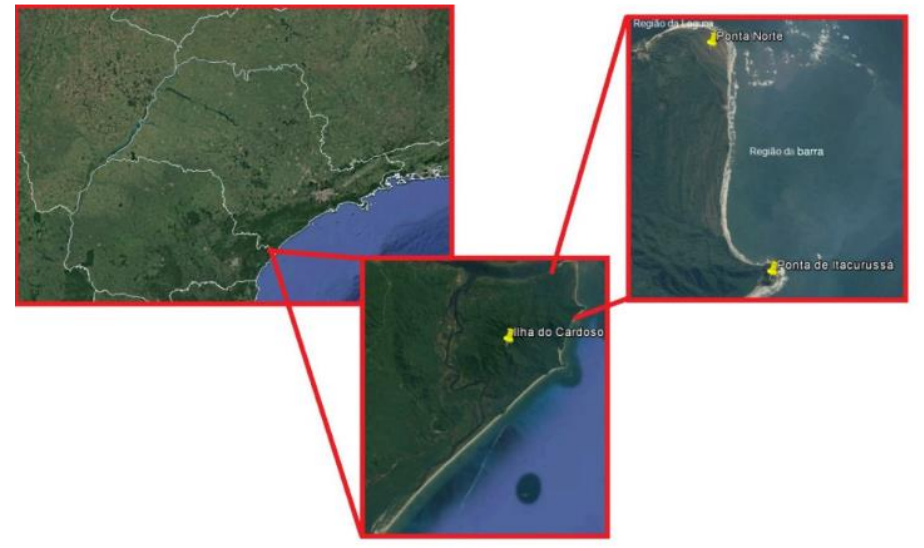

Imagem 1. Localização da área de estudo no complexo lagunar da Ilha do Cardoso-SP.Fonte: Drezza (2017), a partir de composições do Google Earth

\section{Agradecimentos}

Agradeço ao Conselho Nacional de Desenvolvimento Científico e Tecnológico pela disponibilidade da bolsa durante a pesquisa.

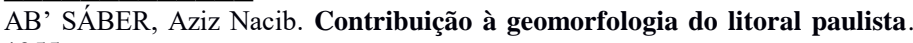
1955.

ARAUJO, R. S., Silva, G. V., Freitas, D., \& Klein, A. H. F. (2009). Georreferenciamento de fotografias aéreas e análise da variação da linha de costa. Métodos en Teledetección Aplicada a la Prevención de Riesgos Naturales en el Litoral, p.123-138.

CHELIZ, P.M., 2015. Ilha do Cardoso: contribuições para compartimentação do relevo. de Gouveia Souza, Celia Regina. "PRAIAS ARENOSAS OCEÂNICAS DO ESTADO DE SÃO PAULO (BRASIL): SÍNTESE DOS CONHECIMENTOS SOBRE MORFODINÂMICA, SEDIMENTOLOGIA, TRANSPORTE COSTEIRO E EROSÃO COSTEIRA." Revista do Departamento de Geografia (2012): 308-371.

DOLAN, R.; HAYDEN, B.P.; MAY, P.; MAY, S.K. 1980. The Reliability of Shoreline Change Measurements from Aerial Photographs. Shore and Beach, v.48, n. 4 , p. 22-29.

NRC (NATIONAL RESEARCH COUNCIL). 1990. Managing Coastal Erosion. Washington: National Academic Press. p.182.

TESSELER, M. G., SUGUIO, K., de Mahiques, M. M., \& FURTADO, V. V. (1990). Evolução temporal e espacial da desembocadura lagunar de Cananéia (SP). Boletim do Instituto Oceanográfico, 38(1), 23-29.

THIELER, E.R.; HIMMELSTOSS, E.A.; ZICHICHI, J.L.; MILLER, T.L. 2005 Digital Shoreline Analysis System (DSAS) version 3.0: An ArcGIS Extension for Calculating Shoreline Change: U.S. Geological Survey Open-file Report 1304.
} 